\section{JTI}

JOURNAL OF

TRAUMA AND INJURY

\title{
Traumatic Bilateral Diaphragmatic Ruptures in a 6-Year-Old Boy
}

\author{
Sung Jin Kim, M.D. ${ }^{1}$, Hyuck Kim, M.D. ${ }^{2}$, Jun Ho Lee, M.D. ${ }^{2}$ \\ ${ }^{1}$ Department of Trauma Surgery, Gachon University Gil Medical Center, Incheon, Korea \\ ${ }^{2}$ Department of Thoracic and Cardiovascular Surgery, Hanyang University Seoul Hospital, Hanyang \\ University College of Medicine, Seoul, Korea
}

Received: July 16, 2017

Revised: November 16, 2017

Accepted: November 18, 2017

Traumatic diaphragmatic rupture is an unusual finding that may occur after blunt trauma. In addition, diaphragmatic rupture occurring bilaterally is extremely rare. We experienced a 6-year-old boy with bilateral diaphragmatic rupture, whom survived after surgical treatment by open thoracotomy but, complicated with spinal cord injury discovered after surgery.

Keywords: Diaphragm; Rupture; Blunt injury

Correspondence to

Hyuck Kim, M.D.

Department of Thoracic and Cardiovascular Surgery, Hanyang University Seoul Hospital, Hanyang University College of Medicine, 222-1 Wangsimni-ro, Seongdong-gu, Seoul 04763 , Korea

Tel: $+82-2-2290-8467$

Fax: +82-2-2220-0699

E-mail: khkim@hanyang.ac.kr

\section{INTRODUCTION}

The diaphragm is a structure which is not only simple but also important that divides the thorax cavity from the abdominal cavity. Traumatic diaphragmatic rupture is relatively rare and it means severe injury. Because of that, clinical and radiographic evaluations for surrounding structures such as the vertebra must be performed in a case of traumatic diaphragmatic rupture. Also, a cord injury without a significant damage of surrounding structures in a radiographic evaluation is rarely seen. Complex injuries of diaphragm rupture and a cord injury mean severe trauma, and they cause unstable vital signs.

\section{CASE REPORT}

A 6-year-old boy visited the emergency room of our hospital with bilateral chest wall pain and dyspnea. He had been hit by a car, sustained blunt trauma as a pedestrian. 


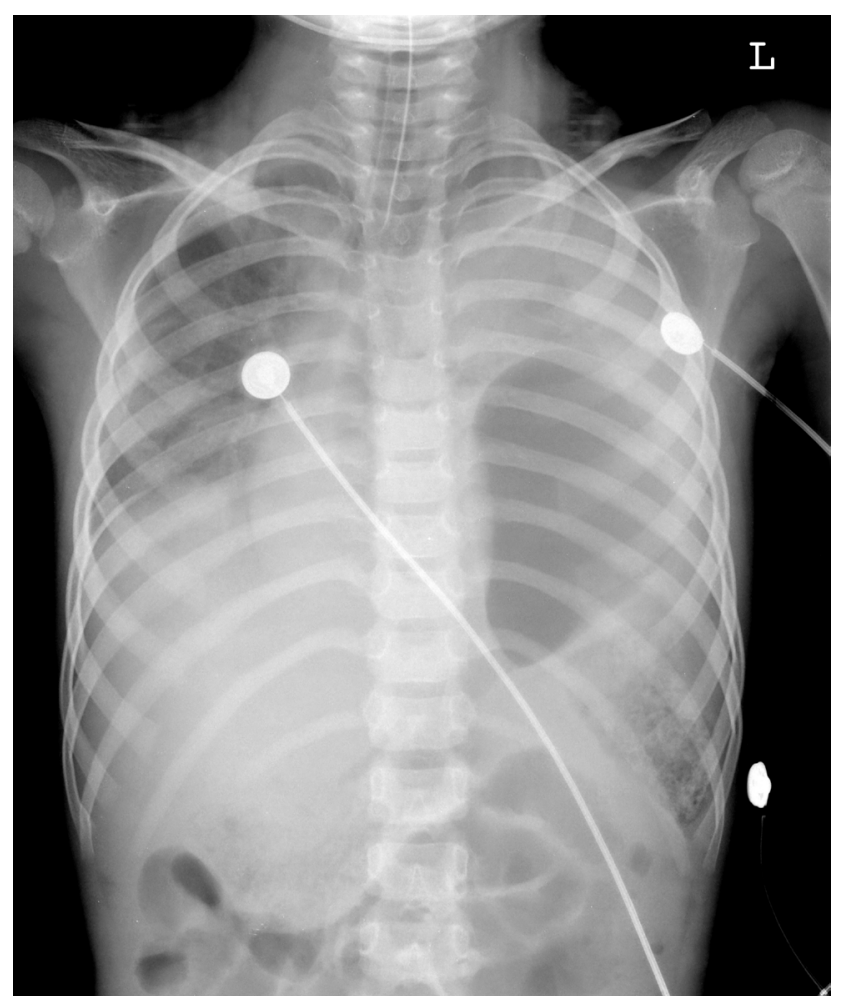

Fig. 1. Preoperative (1st operation) chest X-ray shows elevated stomach into left thorax due to left-sided diaphragmatic rupture and bilateral pleural effusion.

Physical examination presented a rapid heart beat without murmur and decreased breathing sounds in his left lung. He was mentally alert with a pulse rate of 170 per minute, blood pressure of $150 / 100 \mathrm{mmHg}$, and respiratory rate of 38 per minute. The result of arterial blood gas anaylsis was a $\mathrm{pH}$ of $7.17, \mathrm{pCO}_{2}$ of $52.3 \mathrm{mmHg}, \mathrm{pO}_{2}$ of $195.0 \mathrm{mmHg}$, base excess of $-9.5 \mathrm{mmol} / \mathrm{L}$, and oxygen saturation of $98.9 \%$. His chest X-ray showed an elevated left diaphragm (Fig. 1). Intubation was performed immediately, and computed tomography (CT) of his chest and abdomen was done. It showed a herniated elevated stomach into his left thorax due to a left-sided diaphragmatic rupture, bilateral pleural effusion, hematoma at his retrocrural area and hemoperitoneum, and both pelvic bone fractures. Initial laboratory findings before transfer to the operating room, showed a whole blood count of $31,900 / \mathrm{mm}^{3}$, hemoglobin of $9.2 \mathrm{~g} / \mathrm{dL}$, platelet count of $424,000 / \mathrm{mm}^{3}$, and prothrombin time of 12.0 seconds were shown. Troponin-I was 0.05 , in the normal range. Aspartate transaminase of $430 \mathrm{U} / \mathrm{L}$, alanine transaminase

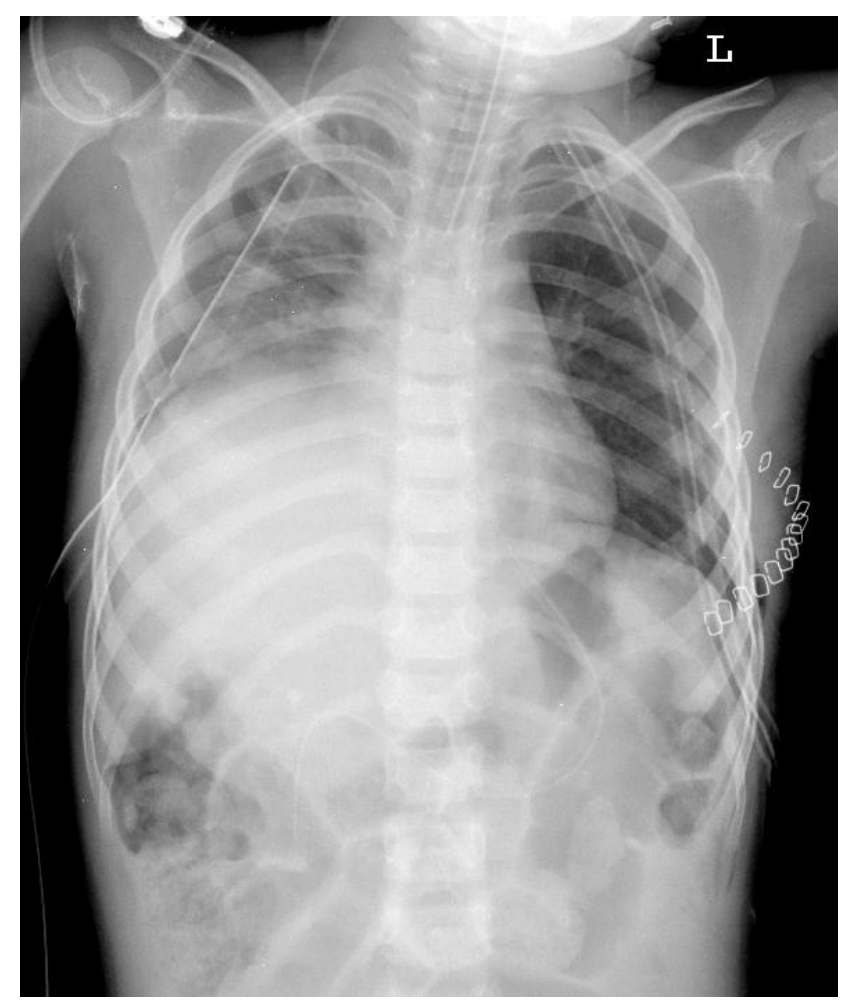

Fig. 2. Preoperative (2nd operation) chest $X$-ray show elevated right diaphragm level.

of $235 \mathrm{U} / \mathrm{L}$, and alkaline phosphatase of $197 \mathrm{U} / \mathrm{L}$ were checked, higher than the normal range.

Immediately, the patient was sent to the operating room, and left lateral thoracotomy via 6th intercostal space was performed. An $8 \times 4 \mathrm{~cm}$ sized laceration was identified through his left diaphragm with hemothorax. Bleeding sites of stomach and intestine were cauterized by electric cautery. After entering abdominal viscera into normal anatomical space, the left diaphragm was restored with a double-layer suture of 2-0 polyester.

On the 1st postoperative day, extubation was done. However, his oxygen saturation gradually decreased, and re-intubation was performed. On follow-up chest X-ray, pleural effusion increased in his right thorax, and closed thoracostomy was done. After the procedure, hazziness over his right thorax was improved. Chest X-ray and chest CT on his 2nd postoperative day presented a gradually elevating right diaphragm into his right thorax (Fig. 2) after our 1st operation, and decision for transfer to the operating room was made with the impression of right-sided diaphragmatic rupture. 


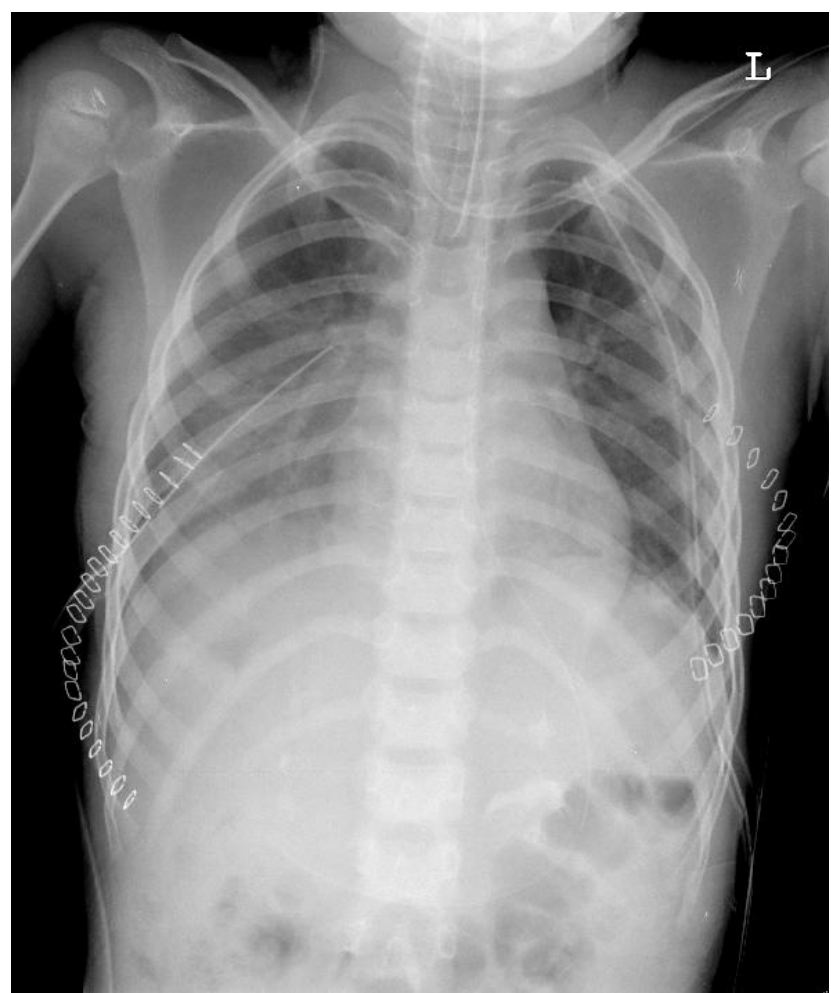

Fig. 3. Chest X-ray on 1-day after 2nd operation.

Right lateral thoracotomy via 7 th intercostal space was performed. $15 \times 7 \mathrm{~cm}$ sized laceration was identified through his right diaphragm with hemothorax. The diaphragm was lacerated at less than $1 \mathrm{~cm}$ from the chest wall. There were no injuries seen over his liver and kidney, but they were also herniated. The viscera were pushed into the abdominal cavity but organs were not able to enter the abdominal cavity due to increased abdominal pressure, such as bowel edema due to trauma and postoperative change. So ruptured site was repaired with $4 \mathrm{~cm} \times 10 \mathrm{~cm}$ sized $2 \mathrm{~mm}$ Gore-Tex ${ }^{\mathrm{TM}}$ patch (W.L. Gore \& Associates, Newark, Delaware, USA) due to too large defects for primary closure. Additionally, lateral and posterior margins for suture were absent. Therefore, adequate repair required passing the sutures around the ribs. After the 2nd operation, vital signs were stable and extubation was done immediately on the day of the operation (Fig. 3).

However, on the 1st postoperative day of the 2 nd operation, the patient was discovered to be paraplegic due to initial injury to his spine which was not discovered earlier because neurologic evaluation of the patient was difficult

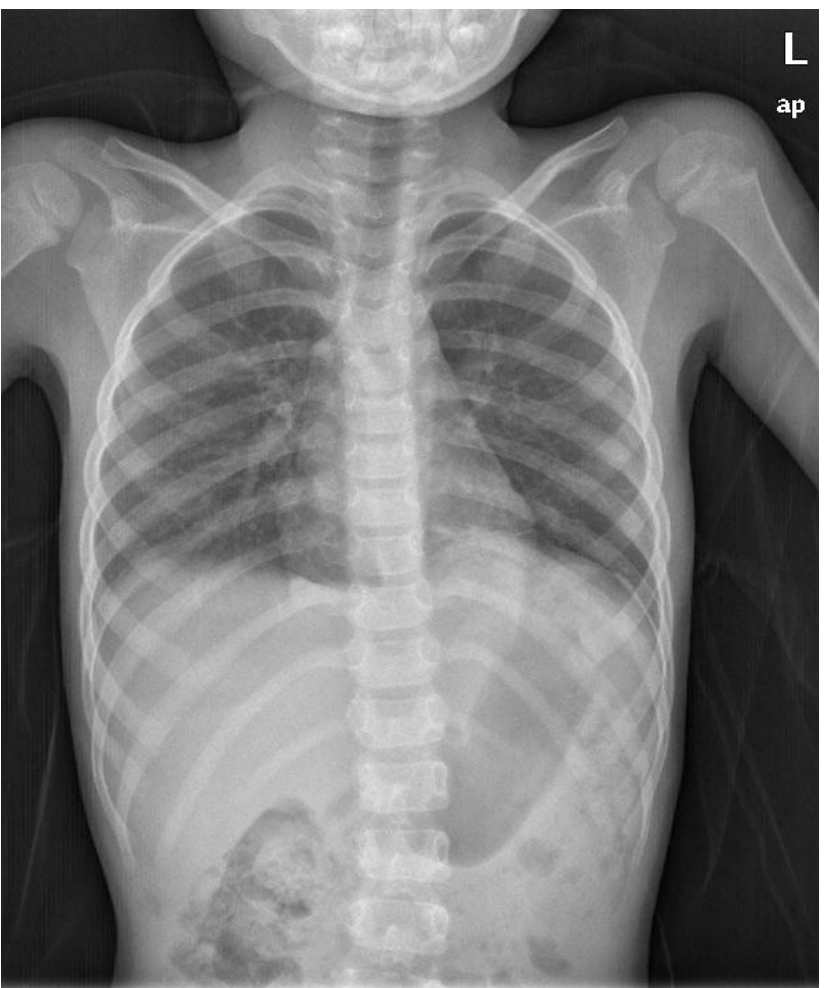

Fig. 4. Chest X-ray. 3rd postoperative week.

due to sedation state. And in the operation field, there were no definitive deformity of spine. Spine 3-dimension $\mathrm{CT}$ and lumbar spine magnetic resonance imaging (MRI) were done. But diffuse cord injury below his fourth thoracic vertebra and diffuse swelling in the conus medullaris with subtle kinking appearance due to trauma were noted on MRI. Consult to our department of neurosurgery was done and the injury was decided to be irreversible.

He stayed in the intensive care unit until the 10th postoperative day of his 2 nd operation, and he was transferred out to the department of rehabilitation medicine on the 3rd postoperative week (Fig. 4). He was discharged on the 7th postoperative week. Careful periodic follow-up was performed and he was without complication such as diaphragmatic eventration, except his paraplegia.

\section{DISCUSSION}

We describe one case of bilateral diaphragmatic rupture in a 6-year-old boy after blunt trauma. To the best of our 
knowledge, there has not been any cases reported in the domestic literature of bilateral diaphragmatic rupture.

Traumatic rupture of diaphragm often results from penetrating or blunt thoracoabdominal trauma. Penetrating trauma from gunshot or stab wounds and blunt trauma caused by motor vehicle accidents are the major etiologic factors. The incidence of diaphragmatic rupture is reported between $0.8 \%$ and $1.6 \%$ of patients arrived at the emergency department of hospital with blunt trauma [1]. Also, traumatic diaphragmatic rupture (TDR) is commonly associated with other organ injuries [2], and associated injuries are responsible for the high mortality and morbidity, chiefly because of pulmonary complications [1].

Wiencek et al. [3] reported that $90 \%$ of TDR cases occurred on the left side. It is because the liver buffers external forces applied to the abdomen. Also, the diaphragm is stronger on the right side than on the left side. And, the detection of diaphragmatic rupture on the right side is more difficult than that on the left side [4].

The simple chest X-ray is the first step to diagnose TDR by the presence of elevation of the diaphragm, herniation of liver or bowel loops, and so on. In our patient, the initial chest X-ray in the emergency room showed left-sided TDR only, and delayed diagnosis of right-sided TDR was done on the 2 nd postoperative day of the 1st operation.

CT of the chest and abdomen is the most reliable and useful diagnostic tool in multiple trauma patients [5]. Disruption of the diaphragm, intrathoracic herniation of the abdominal organs, and other associated injuries can be diagnosed by CT [6]. However, because of patients' unstable vital signs, cases of TDR are found incidentally among $27.2 \%$ of emergency operations for hemoperitoneum or hemothorax without enough preoperative evaluation [7].

Surgery is necessary for treatment, and an immmediate operation is absolutely necessary if it is diagnosed in the early stage. Delayed treatment can increase morbidity and mortality. Death by isolated diaphragmatic rupture is rare, and the main cases of death are hypovolemic shock and acute respiratory failure due to associated injuries to other organs.

The standard method of diaphragmatic repair is simple interrupted suturing or double layer suturing with nonabsorbable surgical suture materials [4]. For small defects, primary closure can be performed. However, in some cases, prosthetic patches are used to close larger defects. Especially, when there were no enough margins for suture at lateral or posterior aspect, adequate repair requires passing the sutures around a rib [8].

Complete cord injury is a complication that remains in this patient. In many papers, cord injury without significant damage to surrounding structure in radiographic evaluation is rarely seen. It occurs mainly in the $\mathrm{C}$ or $\mathrm{T}$ spine level of a young patient under the age of eight who has recieved blunt trauma. If there is any suspicion of cord injury prior to surgery, attention should be paid to the surgical position. In this case, neurology could not be confirmed because of unstable vital signs. Careful positioning should also be taken when cord injury is not identified, as in this patient. And in such a situation, if possible, advancing the operation to the supine position may minimize the deterioration of the cord injury.

In conclusion, prompt and meticulous operation with early diagnosis is essential for increasing the survival rate of TDR. We experienced a 6-year-old boy with bilateral diaphragmatic rupture, whom survived by our surgical treatment.

\section{REFERENCES}

1. Shah R, Sabanathan S, Mearns AJ, Choudhury AK. Traumatic rupture of diaphragm. Ann Thorac Surg 1995;60:1444-9.

2. Yoo DG, Kim CW, Park CB, Ahn JH. Traumatic right diaphragmatic rupture combined with avulsion of the right kidney and herniation of the liver into the thorax. Korean J Thorac Cardiovasc Surg 2011;44:76-9.

3. Wiencek RG Jr, Wilson RF, Steger Z. Acute injuries of the diaphragm. An analysis of 165 cases. J Thorac Cardiovascular Surg 1986;92:989-93.

4. Hwang SW, Kim HY, Byun JH. Management of patients with traumatic rupture of the diaphragm. Korean J Thorac Cardiovasc Surg 2011;44:348-54.

5. Reber PU, Schmied B, Seiler CA, Baer HU, Patel AG, Büechler MW. Missed diaphragmatic injuries and their long-term sequelae. J Trauma 1998;44:183-8.

6. Bosanquet D, Farboud A, Luckraz H. A review of diaphragmatic injury. Resp Med 2009;2:1-6. 
7. Roa G, Madoff HR. Bilateral rupture of diaphragm with delayed strangulation. Chest 1989;95:244-5.

8. Ponn RB. Foramen of Morgagni Hernia. In: Shields TW,
Locicero J, Ponn RB, Rusch VW, eds. General thoracic surgery. 6th ed. Philadelphia:Lippincott Williams \& Wilkins;2005:772-6. 